\title{
Settlement Behaviour of Peat Reinforced With Recycled Waste Tyre Granules
}

\author{
Nor Hazwani Md. Zain ${ }^{1, *}$, Mazlizawati Mustapha ${ }^{1}$, and Abdul Samad Abdul Rahman ${ }^{1}$ \\ ${ }^{1}$ Faculty of Civil Engineering, Universiti Teknologi MARA, 40450, Shah Alam, Selangor, Malaysia
}

\begin{abstract}
Peat is a problematic soil for having high organic content and high water content in nature. This soil is normally avoided for construction as it shows significant primary and secondary settlement even under moderate load. Ground improvement is conducted to improve peat properties by using cement column, soil replacement, chemical and biological stabilisation and others. However, some of these methods have their drawbacks for being non-sustainable to the environment, very costly, ineffectiveness and slow result performance. Alternative method using recycled waste tyre granules is seen as an innovative approach to reduce the settlement behaviour of peat in a more sustainable way. This paper investigates the effect of waste tyre granules on the settlement behaviour of peat. One-Dimensional consolidation test is carried out on natural sample and samples added with $5 \%$ waste tyre granules with and without addition of sand as filler. The settlement curves for all samples do not show distinct separation between primary and secondary compression stages when using Casagrande's method. Sample which is reinforced with $5 \%$ waste tyre granules and sand has lower compression index and swelling index compared to other samples. The coefficient of volume of compressibility for all samples is reduced with increasing stress levels.
\end{abstract}

\section{Introduction}

Peat is a dark brown or black colour highly organic soil which contains more than $75 \%$ organic content. It is formed by decomposition of mosses, sedges, trees and other plants that grow in marshes and other waterlogged condition that has limited oxygen supply. The texture of peat is different from one location to another due to the fibre content, temperature and degree of decomposition [1]. Decomposition is a process which breakdown the original structure of the peat besides changing the chemical composition. The type of decomposition depends on the availability of oxygen supply which governs the rate of the process.

The water content of peat may range from $200 \%$ to $700 \%$ in West Malaysia but can also reach to $2000 \%$ in some countries [2]. Peat contains fibres with loose and porous structure, which able it to hold considerable amount of water. Water is trapped as intercellular water within the micropores, macropores and adsorbed water [3].

As land becomes scarce due to population growth, the construction of roads, structure and infrastructures over this soft ground cannot be avoided. The development on peat is not a straightforward geotechnical solution like any other inorganic soil as the mechanical behaviour for soft mineral soils such as clay and silt can no longer be applied when the organic content is more than $20 \%$ [4]. Failing of buildings to perform its function on poor ground condition may lead to unprecedented casualties to human life.
In the context of geotechnical problems, peat is very problematic when subjected to compressive stress as it unable to support a moderate load as it shows excessive settlement. The settlement of peat is divided into three different stages namely initial compression, primary compression and secondary compression. The initial compression occurs due to compression of pore gas and elastic compression of soil grains. Primary compression is developed as a result of dissipation of excess pore water pressure which causes an increase in effective stress and secondary compression is the additional settlement after primary compression is completed under constant effective stress [1]. Normally primary compression occurs rapidly while the secondary compression is the most significant settlement which contributes to the total settlement of peat. There are several factors which control the compressibility of peat such as fibre content, organic content, in-situ water content, void ratio, permeability, nature and arrangement of soil particles and inter-particle chemical bonding in some of the soils [5].

Many researchers have established several peat improvement methods such as excavation-displacement and replacement, ground improvement and reinforcement such as stage construction and preloading, stone columns, piles, vertical drains or by reducing driving forces by light-weight fill and deep stabilisation using chemical admixtures such as lime, cement and flyash, surface mattresses, surcharge loading, thermal methods and bio-mineralisation $[6,7,8]$. However, some of these methods have been criticised on the basis of

Corresponding author: hazwani_zain@yahoo.co.uk 
high cost and ineffectiveness. For example, removal and replacement, compaction control, stone columns and surcharge loading are rather expensive and the use of cement is not sustainable for the environment.

Therefore, it is urgent to find a new method which is inexpensive, environmentally friendly, accessible and rapid treatment in order to improve the properties of peat ground. The usage of waste products such as tyre waste in various forms has been recently developed and being used in several geotechnical applications ranging from retaining structures, earth embankments, asphalt pavement and paving system, foundation beds and other applications [9]. A tyre is composed of rubber polymer materials strongly reinforced with synthetic fibres and high strength steel which produces a material having unique properties such as very high tensile strength, flexibility and high frictional resistance [10]. In Malaysia, the total waste produced annually is 8.2 million or 57,391 tonnes and has been considered as commercial waste as there are no specific regulations on its management [11].

Various research works on the usage of shredded tyre waste tyre chips for civil engineering projects have been reported recently especially for road and embankment construction $[9,11,12,13,14,15]$. Different types of soil were used to mix with $5 \%, 10 \%, 20 \%$ and $30 \%$ of shredded tyre chips either coarse material (sand) or fine materials (clay and peat) for soil improvement. Most of the researchers are looking at the strength behaviour, drainage properties, CBR values and compaction properties of the treated soil. The results obtained from Direct shear test suggest that cohesion and friction angle increased with increasing tyre proportions. Besides, the dry density reduced and optimum moisture content increased with increasing dosage of tyre. The CBR values also increased as the stiffness of the sample treated with tyre material improved significantly.

There is limited study investigating the effect of shredded tyre chips on the settlement behaviour of peat. Hence, the aim of this research is to investigate the effect of adding different percentages of tyre granules on compressibility behaviour of peat soil. Some samples were added with sand as filler for the purpose to limit the increase in coefficient of permeability in peat and tyre granules.

\section{Materials and method}

\subsection{Materials}

The peat used in this study was collected from a specific site in Selangor state of Malaysia. The site area is a farm area located along Jalan Johan Setia, Klang, Selangor as shown in Figure 1. Recycled waste tyre granules contain $0.03 \%$ steel wires and nylon fibres passing 5-8 mm sieve with a density of $1.15-1.20 \mathrm{~g} / \mathrm{cm}^{3}$ were used as reinforcing material. The tyre granules are shown in Figure 2.

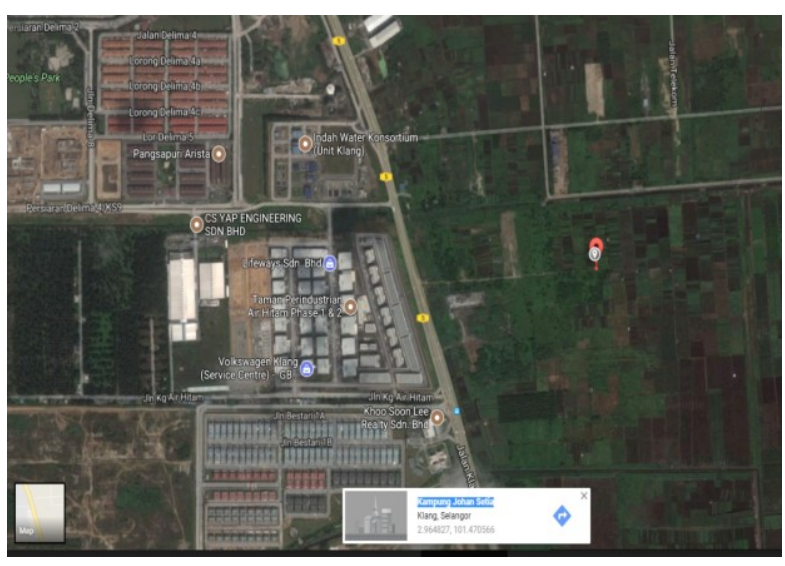

Fig. 1.The location of peat sample used in this study.

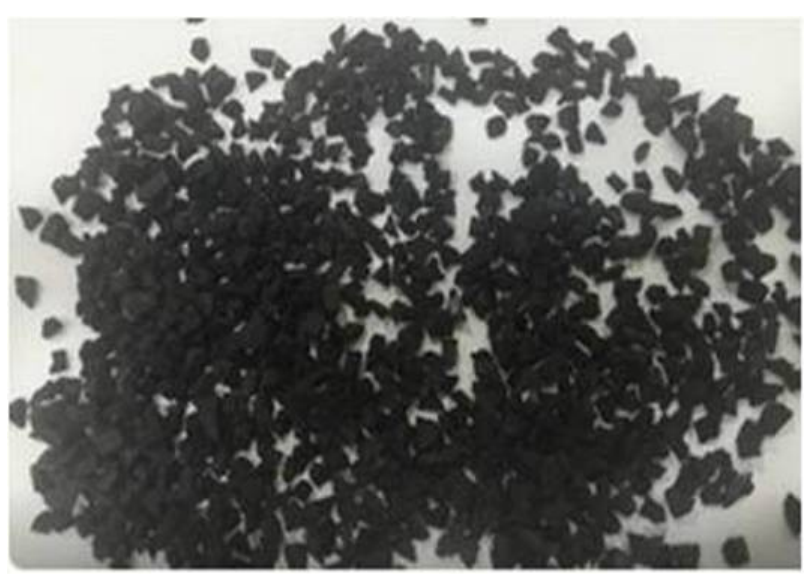

Fig. 2.Recycled waste tyre granules material.

\subsection{Preparation of samples}

Peat soil was firstly air-dry on a tray until reaching at least $200 \%$ gravimetric moisture content. Then, partially dried peat was sieved on a $2 \mathrm{~mm}$ mesh sieve aperture in order to remove large particles. Particles which are smaller than $2 \mathrm{~mm}$ were used for preparing the admixtures. Drying organic material in high-temperature oven should be avoided in order to prevent degradation organic matter. The consistency of the sampling is very important for peat as the moisture content can easily dry out. Hence, the water content of the sample before mixing should always be checked regularly. In order to prepare the samples, around $700 \mathrm{~g}$ of peat soil were thoroughly mixed with $5 \%$ waste tyre granules using a gloved hand for 10 minutes. In this research, $5 \%$ waste tyre granules were used as this percentage is the minimal amount that can influence soil properties. The other sample was also prepared in the same manner, but sand particles were added at a constant amount in the peat and tyre granules mixture. The amount of sand added was half of the total weight of the peat soil. Each sample was then compacted for 27 numbers of blows in one layer using Standard Proctor Test. Then, the specimen was extruded from the compaction mould using $50 \mathrm{~mm}$ diameter and $20 \mathrm{~mm}$ height consolidation ring. All the 
specimens were then tested for One-Dimensional Consolidation Test.

The details of the sample used in this study are shown in Table 1 below:

Table 1. Summary of physical properties test results.

\begin{tabular}{|c|l|}
\hline Sample number & \multicolumn{1}{|c|}{ Sample description } \\
\hline 1 & Natural peat soil \\
\hline 2 & Peat $+5 \%$ waste tyre granules \\
\hline 3 & $\begin{array}{c}\text { Peat }+5 \% \text { waste tyre granules }+50 \% \\
\text { sand }\end{array}$ \\
\hline
\end{tabular}

\subsection{Experimental Program}

\subsubsection{Physical properties tests}

Natural peat was tested for moisture content and specific gravity which in accordance to BS:1377:2 (1990) while for $\mathrm{pH}$ was based on BS:1377:3 (1990). The organic content and fibre content are following the ASTMD2974-7a (Method C) [16] and ASTM-D-1997-91 standards [17].

\subsubsection{Engineering properties tests}

One-Dimensional test is based on BS 1377: Part 5: 1990. Loading pressures of $6,12,25,50$ and $100 \mathrm{kPa}$ and unloading pressures of 200, 50 and $12 \mathrm{kPa}$ were applied on natural peat, peat with $5 \%$ tyre granules and peat with $5 \%$ tyre granules with sand. For each stage of loading and unloading, samples were left for 3 days. This is to allow the development of secondary compression to be completed under constant effective stress. Once reaching the last stage, the samples were checked for the final moisture content.

\section{Results and discussion}

\subsection{Physical Properties test}

The peat obtained is a brownish black in colour containing decomposed plants such as leaves and stems. The natural moisture content of the sample is $617.9 \%$ which seems reasonable for peat located in Peninsular Malaysia. According to [2], the range of moisture content for Peninsular Peat is between 200-700 \%. The organic content is around $84.2 \%$ which considered as peat for having more than $75 \%$ as proposed by [4]. For fibre content, the peat sample consists of $47.7 \%$ fibres which considered as Hemic Peat according to ASTM D 1997. Based on the von Post scale, the peat is classified as H5-H6 with an intermediate degree of decomposition and recognisable plant structure. Specific gravity of peat recorded is 1.38 which is within the typical range of peat reported by [2]. The $\mathrm{pH}$ of peat is around 3.02 and considered as very acidic according to [4].

\subsection{Engineering properties test}

The results of the One-Dimensional Consolidation test for all the tested samples are discussed as follows:

\subsubsection{Settlement Curves}

Typical time-settlement curves for one of the tested samples at different stress levels are shown in Figure 3. After 3 days of loading, the curves show almost flat profile for stress levels 6 to $25 \mathrm{kPa}$. This implies that the classical consolidation theories cannot be applied since the distinction between primary and secondary compression cannot be justified. However, at $100 \mathrm{kPa}$ and $200 \mathrm{kPa}$, the curves are similar like Type 2 curve which indicated by [18] where no inflection point is identified which results to difficulty to estimate the end of primary compression time. Hence, the measurement of excess pore water pressure is necessary to overcome the problem. However, this is beyond the scope of this paper. The analysis of consolidation test results depends on the accuracy of estimating the end of primary compression either by using Logarithmic time fitting method (Casagrade's method), Square root time method (Taylor's method) and pore water measurements [19].

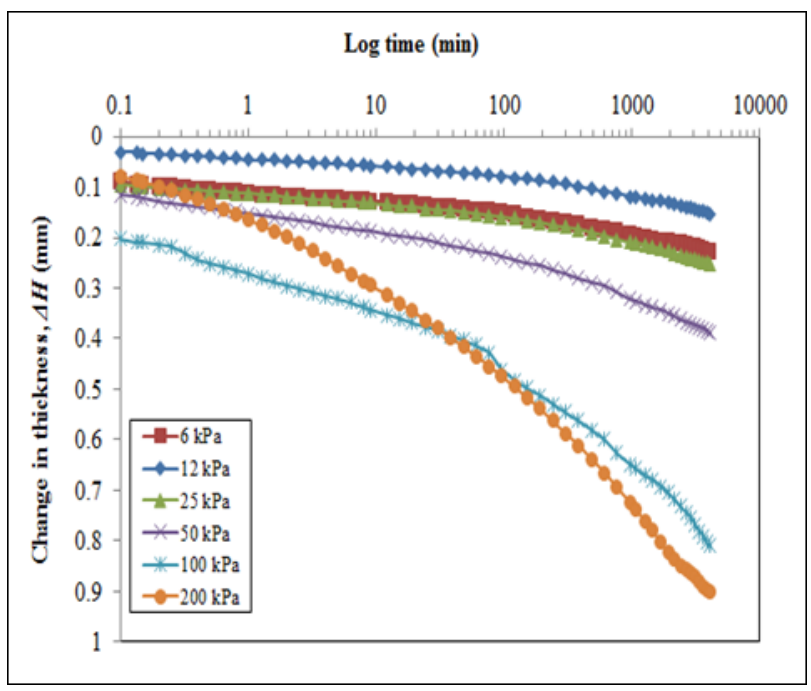

Fig. 3.Time-settlement curves for peat $+5 \%$ waste tyre granules $+50 \%$ sand.

\subsubsection{Compression index and swelling index}

Figure 4 shows the results of void ratio, $e$ versus $\log$ effective vertical stress, $\log \sigma^{\prime}{ }_{v}$. The $C_{c}$ and $C_{s}$ values are obtained by determining the gradient of loading line (compression) and unloading (swelling) line respectively. As expected, sample which is mixed with $5 \%$ waste tyre granules and constant amount of sand shows stiffer response as it represents the lowest $C_{c}$ value compared to sample reinforced with $5 \%$ waste tyre granules only. Original peat has the highest $C_{c}$ among all the samples which describes the highest compressibility behaviour. Upon unloading, swelling capacity greatly reduced for peat treated with waste tyre granules and sand followed by peat reinforced with waste tyre 
granules only and lastly non-reinforced peat. This suggests that adding waste tyre in natural peat able to reduce its compressibility and swelling capacity behaviour. The summary of the results is shown in Table 2 .

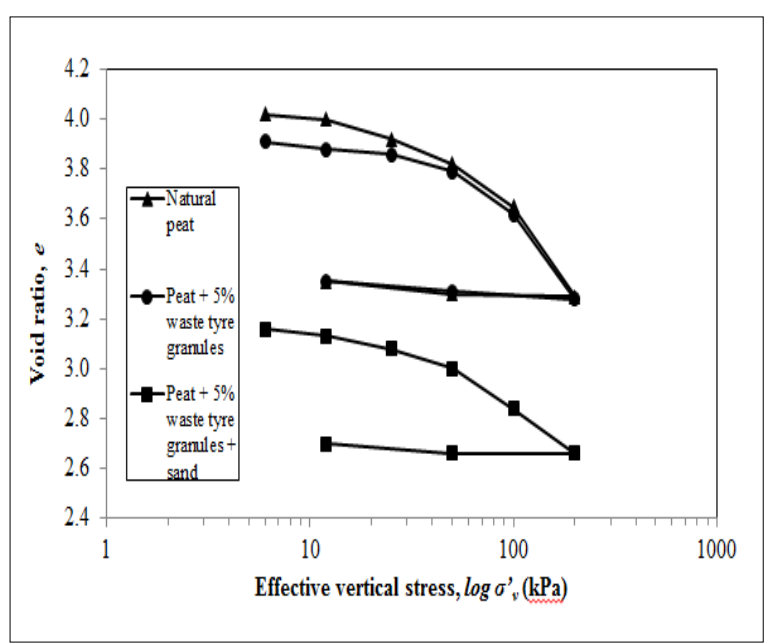

Fig. 4.Compression index, $C_{c}$ and Swelling index $C_{s .}$.

Table 2. Summary of Compression index, $C_{c}$ and Swelling index, $C_{s}$ for the tested samples.

\begin{tabular}{|c|c|c|c|}
\hline $\begin{array}{c}\text { Sample } \\
\text { number }\end{array}$ & Sample description & $\boldsymbol{C}_{\boldsymbol{c}}$ & $\boldsymbol{C}_{\boldsymbol{s}}$ \\
\hline 1 & Natural peat soil & 0.88 & 0.05 \\
\hline 2 & $\begin{array}{c}\text { Peat }+5 \% \text { waste tyre } \\
\text { granules }\end{array}$ & 0.85 & 0.04 \\
\hline 3 & $\begin{array}{c}\text { Peat }+5 \% \text { tyre granules } \\
+50 \% \text { sand }\end{array}$ & 0.56 & 0.03 \\
\hline \multicolumn{2}{|c}{} \\
\hline
\end{tabular}

\subsubsection{Coefficient of volume compressibility, $m_{v}$}

A relationship between coefficient of volume of compressibility, $m_{v}$ and effective vertical pressure, $\log$ $\sigma_{v}{ }_{v}$ is established in Figure 5. It is observed that $m_{v}$ values decrease when the effective vertical stress $\sigma^{\prime}{ }_{v}$ increases for all the tested samples. Peat with $5 \%$ waste tyre granules exhibits almost consistent volume change behaviour compared to other samples. Natural peat has the highest $m_{v}$ values especially at 50 to $200 \mathrm{kPa}$ which is approximately $0.72-0.74 \mathrm{~m}^{2} / \mathrm{MN}$ compared to other samples. The uneven response of $m_{v}$ values for natural peat and peat reinforced with $5 \%$ waste tyre granules are most probably because of the drainage condition of the samples during consolidation stage. Some of the air voids contain in these samples are filled up with waste tyre granules and some are empty which result to different compressibility response.

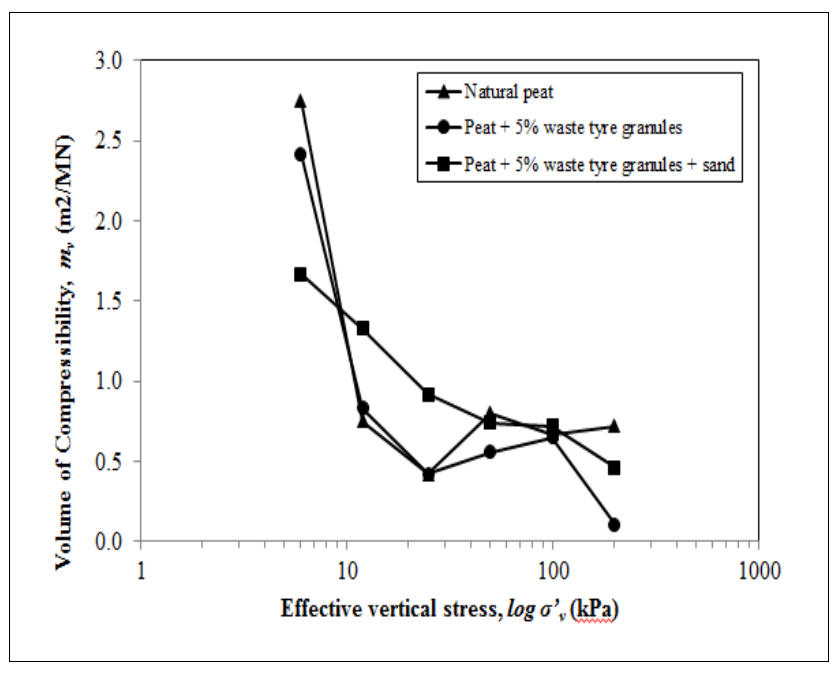

Fig. 5.Void ratio, $e$ versus log effective vertical stress, $\log \sigma^{\prime}{ }_{v}$ graph for peat with $5 \%$ waste tyre granules and sand, peat with $5 \%$ waste tyre granules and natural peat.

\section{Conclusions}

The following are the conclusions drawn from the experimental study:

1. The settlement-time curves for all samples do show the typical consolidation curve when plotted using Casagrande's method. The end of primary consolidation cannot be distinguished by using One-Dimensional Consolidation test without pore pressure measurements.

2. Adding recycled waste tyre granules able to improve the compressibility behaviour of natural peat soil. The addition of sand to sample containing natural peat and waste tyre further able to show better improvement in compressibility behaviour. Untreated sample shows the highest compression index $\left(C_{c}\right), 0.88$ followed by tyre treated sample, 0.85 and sand-tyre treated sample, 0.56 .

3. Peat which is reinforced with waste tyre and sand shows almost consistent volume change compared to other samples. The natural sample shows the coefficient volume change, $m_{v}$ is in the range of 2.75 to $0.72 \mathrm{~m}^{2} / \mathrm{MN}$ while peat with waste tyre only is in the range of. 2.42 to $0.11 \mathrm{~m}^{2} / \mathrm{MN}$. Peat reinforced with tyre waste and sand is in the range of 1.67 to 0.4

The authors acknowledge the assistance of Mohd Akhbar Abdul Hamid and Muhammad Fuad Ahmad with the geotechnical laboratory testing, postgraduate student, Zetty Yusof for sharing her knowledge and experience in sampling and Darren Khoi for his cooperation in supplying waste tyre granules material. The authors would also like to thank the reviewers for their constructive comments in this publication. 


\section{References}

1. S. Kazemian, B. B. K. Huat, A. Prasad, and M. Bargchi, A state of art review of peat: Geotechnical engineering perspective. Int. J. Phys. Sci., Vol. 6, no. 8, pp. 1974-1981, 2011.

2. B. B. K. Huat, S. Kazemian, A. Prasad, and M. Barghchi, State of an art review of peat: General perspective. Int. J. Phys. Sci., Vol. 6, no. 8, pp. 1988-1996, 2011.

3. B. C. O'Kelly and S. P. Pichan, Effects of decomposition on the compressibility of fibrous peat - A review. Geomech. Geoengin., Vol. 8, no. 4, pp. 286-296, Dec. 2013.

4. B. B. K. Huat, A. Prasad, A. Asadi, and S. Kazemian, Geotechnics of Organic Soils and Peat. CRC Press, 2014.

5. G. Mesri and M. Ajlouni, Engineering Properties of Fibrous Peats. Geotech. Geoenvironmental Eng., Vol. 133, no. 7, pp. 850-866, 2007.

6. P. K. Kolay, H. Y. Sii, and S. N. L. Taib, Tropical peat soil Stabilization using class F pond ash from coal Fired power plant. Int. J. Civ. Environ. Eng., Vol. 3, no. 2, pp. 79-83, 2011.

7. M. A. Rahgozar and M. Saberian, Geotechnical properties of peat soil stabilised with shredded waste tyre chips. in Mires and Peat, 2016, Vol. 18, no. 3, pp. 1-12.

8. I. Chang, I. Jooyoung, and G. C. Cho, Introduction of microbial biopolymers in soil treatment for future environmentally-friendly and sustainable geotechnical engineering. Sustainability, Vol. 8, no. 251, pp. 1-23, 2016.

9. A. V. Ratnam, D. S. V Prasad, G. V. R. Prasada Raju, and P. Sowmya Ratna, Influence of Waste Tyre Rubber Chips on Strength and Settlements of Soils. Int. J. Eng. Innov. Res., Vol. 5, no. 4, pp. 2277-5668, 2016.

10. B. B. K. Huat, A. A. Aziz, and L. W. Chuan, Application of scrap tires as earth reinforcement for repair of tropical residual soil slope. Electron. J. Geotech. Eng., Vol. 13, 2008.

11. N. N. Nik Daud, Z. M. Yusoff, and A. S. Muhammed, Ground Improvement of Problematic Soft Soils Using Shredded Waste Tyre, Jordanian Int. Civ. Eng. Conf., Vol. 6, pp. $1-5,2015$.

12. R. Ayothiraman and A. K. Meena, Improvement of Subgrade Soil with Shredded Waste Tyre Chips. in Proceedings of Indian Geotechnical Conference, 2011, pp. 365-368.

13. P. Promputthangkoon and B. Karnchanachetanee, Geomaterial prepared from waste tyres, soil and cement.Procedia Soc. Behav. Sci., Vol. 91, pp. 421-428, 2013.

14. M. Saberian and M. A. Rahgozar, Geotechnical properties of peat soil stabilised with shredded waste tyre chips in combination with gypsum lime or cement. Mires Peat, Vol. 18, no. 16, pp. 1-16, 2016.

15. G. S. Hambirao and P. G. Rakaraddi, Soil Stabilization Using Waste Shredded Rubber Tyre Chips. IOSR J. Mech. Civ. Eng., Vol. 11, no. 1, pp. 20-27, 2014.

16. ASTM, D2974-07a: Standard Test Methods for Moisture, Ash and Organic Matter of Peat and Other Organic Soils. ASTM Int., pp. 1-4, 2007.

17. ASTM, D1997-91: Standard Test Method for Laboratory Determination of the Fiber Content of Peat Samples by Dry Mass. ASTM Int., Vol. 91, no. Reapproved 2008, pp. 1-2, 2008.

18. N. Gofar and Y. Sutejo, Long term compression behaviour of fibrous peat. Malaysian J. Civ. Eng., Vol. 19, no. 2, pp. 104-116, 2007.

19. B. H. Koti Reddy, R. B. Sahu, and S. Ghosh, Consolidation Behavior of Organic Soil in Normal Kolkata Deposit. Indian Geotech. J., Vol. 44, no. 3, pp. 341-350, 2014.

Corresponding author: hazwani_zain@yahoo.co.uk 